\title{
Effect of walking on the ocular tension in open-angle glaucoma
}

\author{
D. A. LEIGHTON
}

Manchester Royal Eye Hospital

In a previous paper (Leighton and Phillips, 1970) it was shown that a fall in ocular tension $\left(\mathrm{P}<\mathbf{0}^{\circ} \mathrm{OI}\right)$ occurred in the right and left eyes of fourteen healthy young adults after 50 minutes' brisk walking. The result was as significant when a "correction" was made for the change in ocular tension during a control period of sitting on another day. The magnitude of the fall was dependent on the height of the initial ocular tension; right eyes 0.0 I $<\mathrm{P}<0.05$, left eyes $\mathrm{P}<0.01$.

It would obviously be useful to know if this trend is also present in patients with openangle glaucoma. The effect on the ocular tension of a walk along an urban road was therefore compared with the effect of sitting in twelve patients with open-angle glaucoma.

\section{Subjects and methods}

Twelve recently diagnosed untreated cases of open-angle glaucoma* (five males and seven females) whose mean age was 67.4 years (range 58 to 83 ), attended on two consecutive mornings, I and II, for the tests:

(1) Applanation tensions from both eyes: blood pressure from right arm: sitting for 50 minutes.

(2) Applanation tensions from both eyes: blood pressure from right arm: on one morning, walking for 50 minutes: on the other morning, sitting for 50 minutes.

(3) Applanation tensions from both eyes: blood pressure from the right arm.

The order in which patients walked or sat was randomized so that, of the twelve subjects, six exercised on day I and rested on day II, and six rested on day I and exercised on day II. Each phase of the investigation was done at the same time on the two consecutive mornings. A technician recorded the ocular tensions first from the right eye, then the left using a Goldmann applanation tonometer. Measurements of blood pressure (by D.A.L.) were taken from the right arm with the patient seated immediately after each applanation reading.

\section{Results}

OGULAR TENSION

Differences between applanation tensions 2 and 3 immediately before and after walking or sitting for right and left eyes are shown in Table I and the Figure (opposite). The mean fall after walking was $4.5 \mathrm{~mm} . \mathrm{Hg}$ in right and left eyes $(\mathrm{P}<0.00 \mathrm{I}$ each), and after sitting there were mean falls of $0.83 \mathrm{~mm} . \mathrm{Hg}(0.0 \mathrm{I}<\mathrm{P}<0.02)$ in the right eyes, and $0.67 \mathrm{~mm} . \mathrm{Hg}$ $(\mathrm{P}>0.05)$ in the left eyes. When the fall after sitting was used as a control activity and subtracted from the fall after walking, the corrected fall after walking was again significant (right eyes $\mathrm{P}<0 \cdot 0$; left eyes $\mathrm{P}<0 \cdot 00 \mathrm{I}$ ). 
Table I Changes in applanation tension $(\mathrm{mm} . \mathrm{Hg})$ after walking and sitting, and the change after walking compared with the change after sitting in twelve patients with open-angle glaucoma

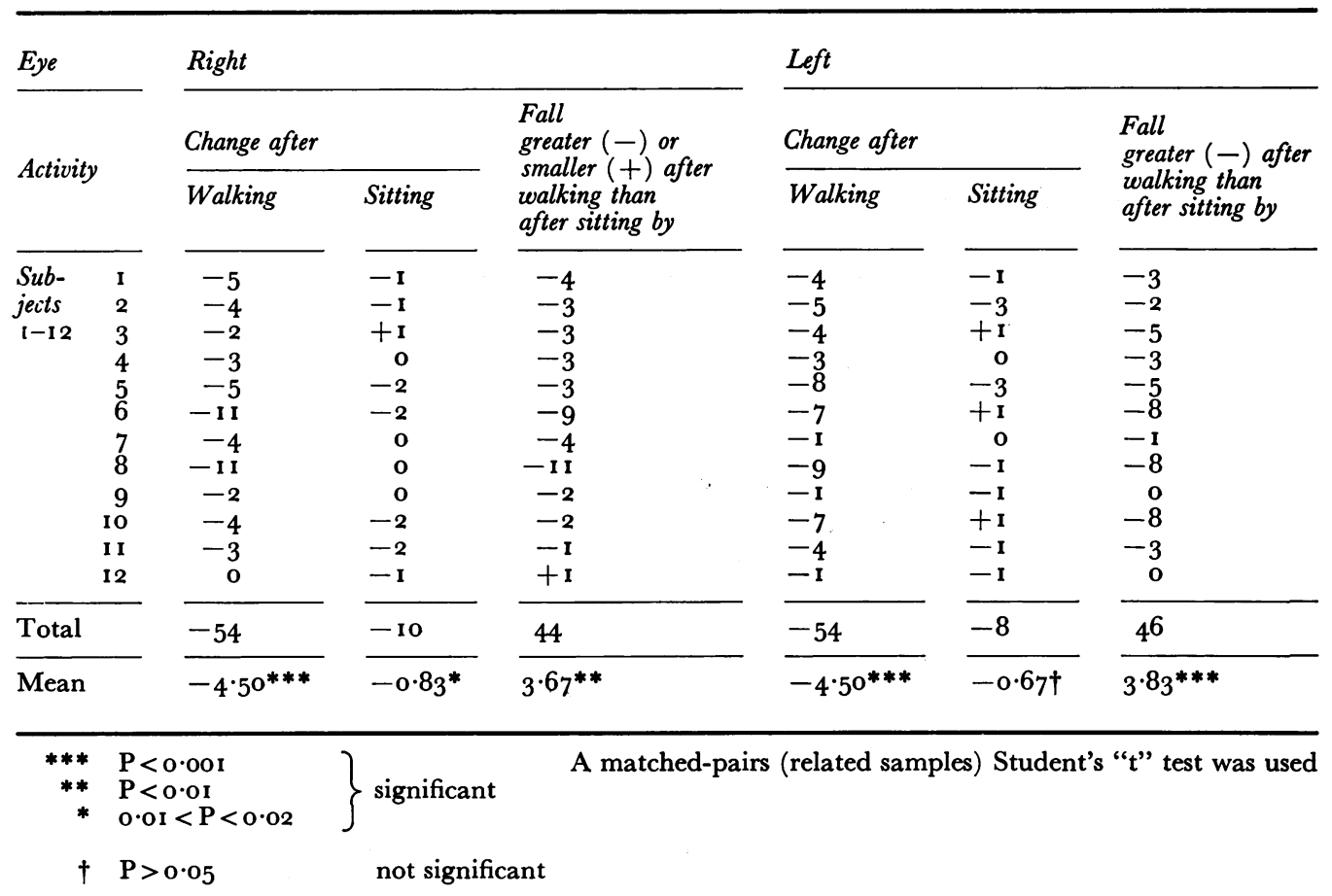

EFFECT OF WALKING
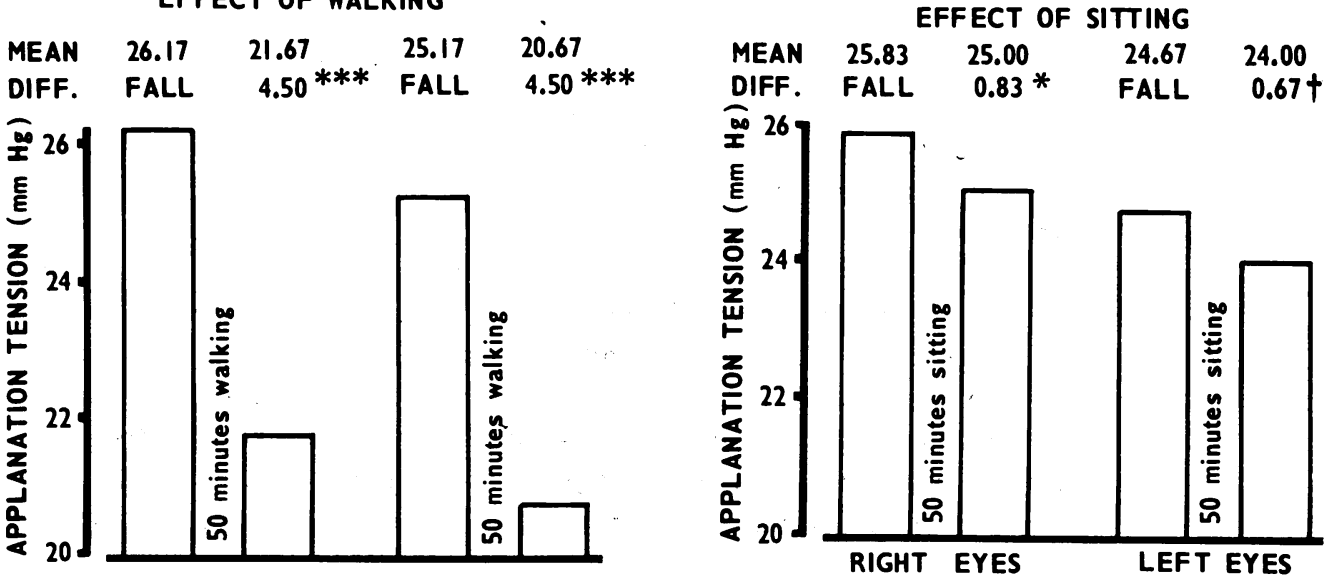

F I G U R B Bar charts showing mean applanation tensions (mm.Hg) from right and left eyes of 12 patients with open-angle glaucoma before and after:

LEFT 50 minutes walking RIGHT 50 minutes sitting

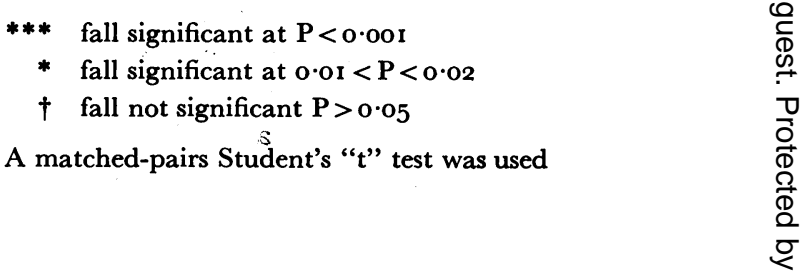


A tendency for a greater fall in ocular tension to occur with a higher ocular tension before walking was present in both eyes, but reached significance only for right eyes; correlation coefficients were: right eyes $+0.646 ; 0.01<\mathrm{P}<0.05$, and left eyes +0.454 ; $\mathrm{P}>0 \cdot 05$.

\section{BLOOD PRESSURE}

Changes in blood pressure recorded from the right arm are given in Table II.

The mean systolic blood pressure fell significantly after walking $\left(\mathrm{t}=2 \cdot 95^{8}, \mathrm{o} \cdot \mathrm{O} \mathrm{I}<\mathrm{P}<\right.$ $0 \cdot 02)$. A fall after sitting was not significant (see Table II) $(\mathrm{t}=\mathrm{I} \cdot 94 \mathrm{I}, 0 \cdot 05<\mathrm{P}<0 \cdot \mathrm{I} 0)$. The fall after walking was greater than the fall after sitting but the difference was not significant. Changes in the diastolic pressure were negligible.

Table II Mean blood pressure from right arm when seated before and after walking or sitting, each for $5^{0}$ minutes on two consecutive mornings in randomized order in twelve patients with open-angle glaucoma

\begin{tabular}{|c|c|c|c|c|}
\hline \multirow{2}{*}{$\begin{array}{l}\text { Mean blood pressure } \\
(\mathrm{mm} . \mathrm{Hg})\end{array}$} & \multicolumn{2}{|c|}{ Walking } & \multicolumn{2}{|l|}{ Sitting } \\
\hline & Before & After & Before & After \\
\hline Systolic & 143 & $134^{*}$ & 138 & 132 \\
\hline Diastolic & 82 & $8 \mathrm{I}$ & 79 & $8 \mathrm{I}$ \\
\hline
\end{tabular}

*fall significant at $0.01<\mathrm{P}<0.02$

A matched-pairs (related samples) Student's " $t$ " test was used

\section{Discussion}

The type of exercise undertaken by the twelve patients, a "stroll" along an urban road, was quite moderate. Marcus, Krupin, Podos, and Becker (1970) exercised twelve normal subjects maximally on a treadmill jogger for 4 minutes. A resultant fall in ocular tension coincided with a rise in both blood lactate and blood osmolarity, and a fall in blood $\mathrm{pH}$.

Stewart, Le Blanc, and Becker (1970) found a fall in blood pressure after exercise as occurred in the present study (Table II). The fall in ocular tension may have been partly due to the coincidental fall in blood pressure, although no close correlation was found between the magnitude of the fall in ocular tension and that of the fall in blood pressure. Vasodilation in the muscles used in walking may have partly accounted for the fall in blood pressure: blood would tend to be diverted towards muscle and away from other organs, including the eye. Adrenergic activity would play a part in making these circulatory readjustments.

\section{GIRGADIAN VARIATION IN OGULAR TENSION}

The reduction in ocular tension found after walking was superimposed on a circadian variation which showed an almost consistent fall in mean values. Hence, in Table III (opposite), comparisons $(a),(b),(f),(g),(h),(j)$ showed with one exception a fall in ocular tension. In $(h)$, after sitting, falls of $0.83 \mathrm{~mm}$. in right eyes (significant at $0.01<\mathrm{P}<0.02$ ) and of $0.67 \mathrm{~mm}$. in left eyes (not significant at $\mathrm{P}<0.05$ ) were found. In $(j)$, between the 
first and third applanation readings when patients sat, ocular tensions fell by $2 \cdot 25 \mathrm{~mm}$. in right eyes (significant at $0.02<\mathrm{P}<0.05$ ) and $\mathrm{I} \cdot 08 \mathrm{~mm}$. in left eyes (not significant at $\mathrm{P}>0 \cdot 05)$.

Table III Difference between mean applanation tension readings I, 2, and 3 taken on two consecutive mornings in twelve patients with open-angle glaucoma

(a) to $(j)$ each refer to comparisons between paired mean applanation readings, $\mathrm{I}, 2$, or 3 (i.e. $\mathrm{I}-2,2-3$, or $\mathrm{I}-3$ ). Except in one instance (comparison $(f)$ for right eyes) the mean ocular tension always fell

Comparisons between mean

applanation tensions $\mathrm{I}$ and 2

\begin{tabular}{ccc}
\hline & $\begin{array}{c}\text { Mornings } \\
\text { or }\end{array}$ & $I I$ \\
\hline
\end{tabular}

Fall in

mean applanation tension

$(\mathrm{mm} . \mathrm{Hg})$

on mornings I or II

Mean applanation

tension

Mean applanation tension

\begin{tabular}{lll}
\hline 1 & 2 & 3 \\
\hline
\end{tabular}

(a) $\mathrm{I}$

(b)

(c) $\mathbf{I}$

(d)

(e) I

2

\begin{tabular}{lll}
\hline 1 & 2 & 3 \\
\hline
\end{tabular}

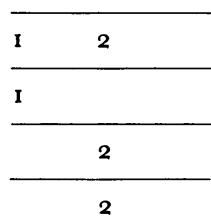

\begin{tabular}{|c|c|}
\hline Right eyes & Left eyes \\
\hline$-0.5^{8}$ & -0.25 \\
\hline$-0 \cdot 42$ & $-0 \cdot 4^{2}$ \\
\hline-0.83 & $-\mathbf{I} \cdot 00$ \\
\hline-0.67 & $-1 \cdot 07$ \\
\hline$-1 \cdot 17$ & $-I \cdot 4^{2}$ \\
\hline
\end{tabular}

I and II refer to first and second mornings respectively of investigation in chronological order (i.e. irrespective of whether walking or sitting). Between applanation tensions 2 and 3 subjects walked or sat for 50 minutes, and the order in which this was done was randomized so that on mornings I or II, six subjects walked and six subjects sat. Differences between mean applanation tensions 2 and 3 have therefore not been included

Comparisons between mean applanation

tensions $\mathrm{I}-2,2-3$, or $\mathrm{I}-3$

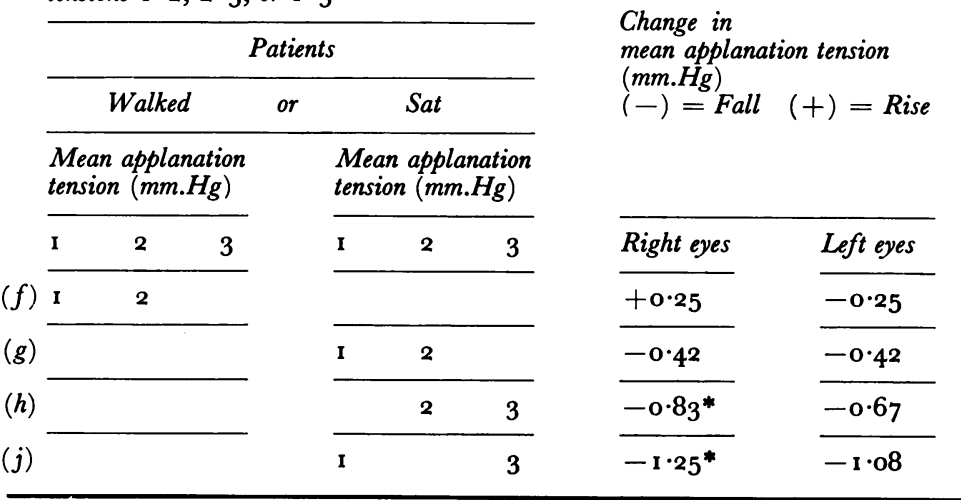

The differences between applanation tensions 2 and 3 before and after walking are already included in Table I

A significant fall (*), $0 \cdot 0 \mathrm{I}<\mathrm{P}<0.05$, occurred in only two examples A matched-pairs Student's " $t$ " test was used 
DIFFERENGES BETWEEN OGULAR TENSIONS ON THE TWO CONSEGUTIVE DAYS

Comparisons $(c),(d)$, and $(e)$ show that mean ocular tensions I and 3 were consistently lower on morning II than on morning I, hence the importance of randomization in the order of walking and sitting. Bankes, Perkins, Tsolakis, and Wright (1968) and Leighton and Phillips (1970) have commented on the tendency for ocular tension to fall on consecutive days.

The consistent tendency for the ocular tension to fall slightly:

(A) during the two mornings

(B) from morning I to morning II

should be borne in mind when patients are admitted to hospital for "phasing", or monitoring of the ocular tension. The small though consistent falls, $\mathbf{A}$ and $\mathbf{B}$ above, which occurred without any treatment, possibly due to a reduction in apprehension in the patients, may in part be erroneously ascribed to modification in medical treatment. Löhlein (1926) suggested that the variation in ocular tension without treatment should be determined before using medical treatment in glaucoma. Hager (1958) comments on the tendency for the ocular tension of glaucoma patients to fall when they are admitted to hospital even when no treatment is being given. This tendency to fall is probably less than might otherwise occur because of the removal of almost all exercise in hospital.

\section{Summary}

Twelve patients, whose mean age was 67.4 years (range $5^{8}$ to 83 ), with open-angle glaue coma walked gently for 50 minutes on one morning and sat for 50 minutes at the same time of day on another consecutive morning. Six patients walked on Day I and sat on Day IF while the other six sat on Day I and walked on Day II. A mean fall in ocular tension of $4.5 \mathrm{~mm}$. was found in both right and left eyes after walking $(\mathrm{P}<0 \cdot 00 \mathrm{I})$. A fall in ocular tension was also found after sitting, significant $(0 \cdot 0 \mathrm{r}<\mathrm{P}<0 \cdot 02)$ for right eyes only, but the fall after walking was significantly greater; right eyes $\mathrm{P}<0 \cdot 0 \mathrm{I}$, left eyes $\mathrm{P}<0 \cdot 00 \mathrm{I}$. The higher the ocular tension before walking, the greater was the fall. This trend was significant only for right eyes $(0 \cdot 0 \mathrm{r}<\mathrm{P}<0 \cdot 05)$.

A nearly consistent tendency was found for the ocular tension to fall slightly:

(A) during sitting, and

(B) when readings from morning I were compared with those for morning II.

The systolic blood pressure fell significantly after walking (0.01 $<\mathrm{P}<0 \cdot 02)$.

\section{References}

BANKeS, J. L. K., PERKINS, E. S., tsolakis, s., and Wright, J. E. (I968) Brit. med. F., r, 79I HAGER, H. (1958) "Die Behandlung des Glaukoms mit Miotika". Bucherei des Augenarztes, Beihefte Klin. Mbl. Augenheilk., vol. 29, p. 27. Enke, Stuttgart LEIGHTON, D. A., and PHILlips, c. I. (1970) Brit. F. Ophthal., 54, 599 LÖHLEIN, w. (1926) Klin. Mbl. Augenheilk., 77, 567, and Suppl., p. I MARCUS, D. F., KRUPIN, T., PODOS, s. M., and BECKER, B. (1970) Invest. Ophthal., 9, 749 STEWART, R. H., LE BlANC, R., and Becker, B. (1970) Amer. F. Ophthal., 69, 245 